\title{
Effect of combined strategy on mitigating air pollution in China
}

\author{
Shuwei Jia ${ }^{1}[1$ \\ Received: 19 May 2020 / Accepted: 14 December 2020 / Published online: 14 January 2021 \\ (c) The Author(s), under exclusive licence to Springer-Verlag GmbH, DE part of Springer Nature 2021
}

\begin{abstract}
Air pollution has worsened as a result of increased traffic congestion in cities. Using air pollution caused by motor vehicle emissions (mainly by carbon monoxide, hydrocarbon, nitrogen oxide, and particulate matter) as an example, in this study, we applied an integrated algorithm comprising system dynamics, entropy weight method, and gray system theory to establish a weighted logic function. A vehicle pollutant control model (including the transport, health, and environmental subsystems) was established by VENSIM software. The medium- and long-term key variable analysis showed that the integrated algorithm, fully reflecting the advantages of system dynamics and gray system theory, more accurately described air pollution caused by vehicle emissions. Our research results also revealed that the combined strategy of penalties and air pollution charging fee had a threefold effect: reduced congestion and emissions, improved health impact index, and reduced number of illegal trips. Specifically, the degree of traffic congestion, number of illegal trips, and the degree of air pollution decreased by approximately $82.40 \%, 69.35 \%$, and $68.91 \%$, respectively, whereas the health impact index increased by about $279.03 \%$. This finding provides guidance for improving policy and optimizing management and control modes.
\end{abstract}

Shuwei Jia

shuweijia999666@163.com

1 College of Information and Management Science, Henan

Agricultural University, 15 Longzi Lake, Campus,

Zhengzhou East New District, Zhengzhou 450046, Henan,

People's Republic of China 


\section{Graphic abstract}

(a)

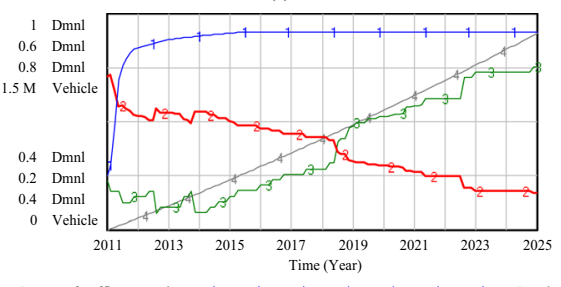

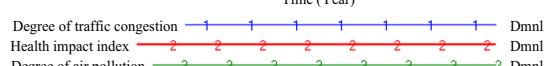

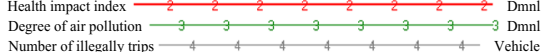

(d)

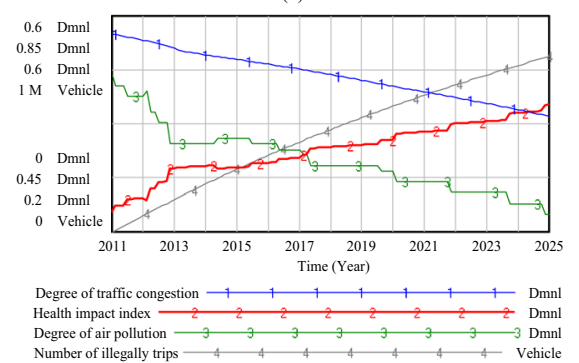

(g)

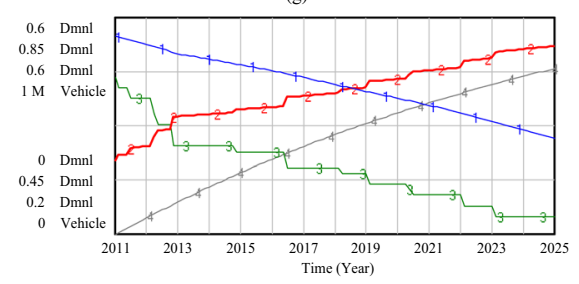

Degree of traffic congestion $-1,1,1,1,1,1,+1, D m n l$ Health impact index $\longrightarrow \mathrm{C}_{2} \mathrm{C}_{3} \mathrm{C}_{3} \mathrm{C}_{3} \mathrm{C}_{3} \mathrm{C}_{3} \mathrm{C}_{3} \mathrm{C}_{3} \mathrm{Dmnl}$ Number of illegally trips
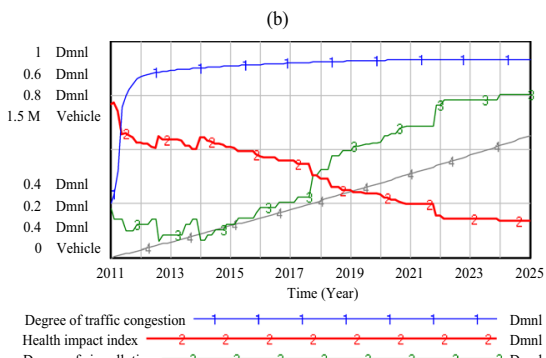
Health impact index
Degree of air pollution
Number of illegally trips

(e)
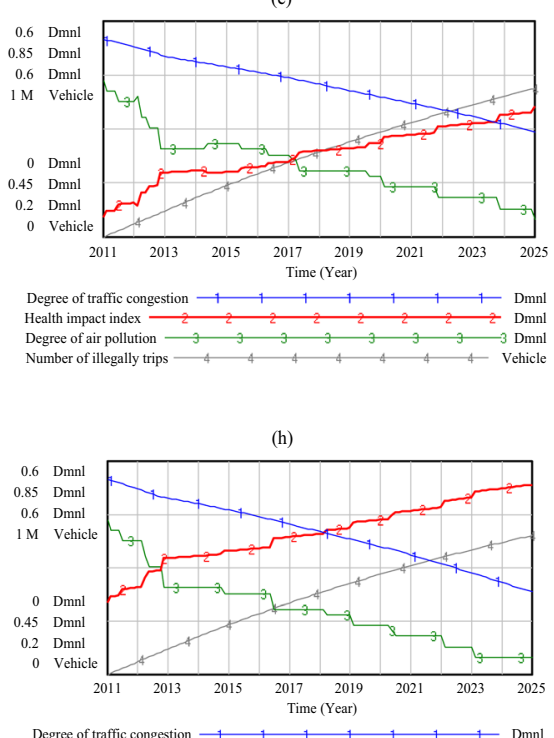

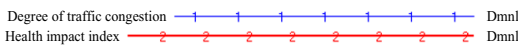

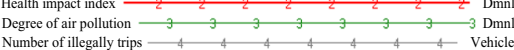
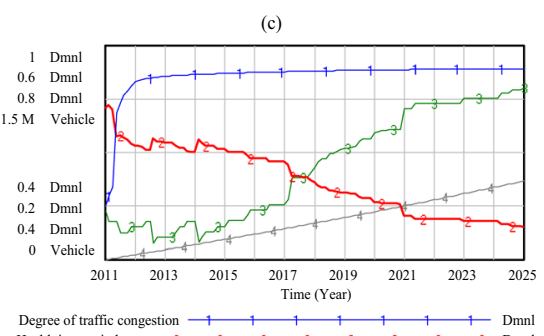

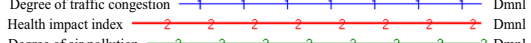
Number of illegally trips

(f)

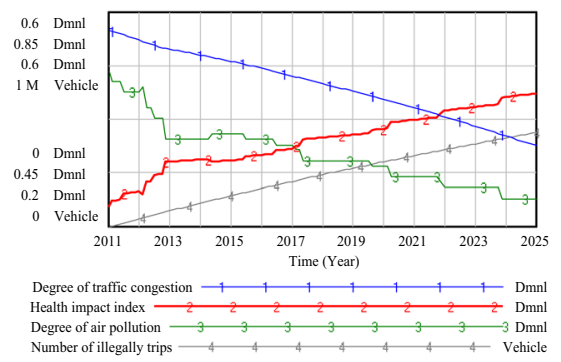

(i)

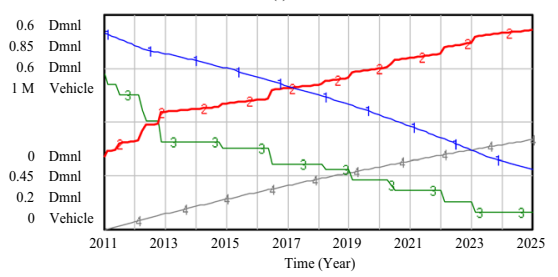

Degree of trafficic congestion $+1+1+1+1+$ Dmnl

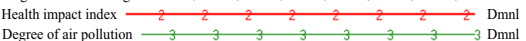
Number of illegally trips

Keywords System dynamics · Air pollution $\cdot$ Integrated algorithm $\cdot$ Emission reduction $\cdot$ Threefold effect

\section{Introduction}

Since 2013, many cities in China have frequently experienced haze pollution. Especially in the past 3 years, the coverage area has expanded rapidly, and the pollution level has risen sharply. Emissions from traffic are among the main influencing factors (MEP 2019). Although the government has adopted policies such as restricting traffic and promoting new-energy vehicles, such problems are still worsening, affecting people's travel, work, and life. Therefore, urban traffic congestion and the air pollution caused by it pose urgent problems that need to be solved. Studying this problem has both theoretical significance and practical value since it can help strengthen research on the management of vehicle emissions and recommend corresponding control strategies.
In recent years, many studies have investigated the abovementioned issues, focusing on areas such as economic means, administrative means, technical means, environmental policy, and health impact. In terms of economic approaches to controlling haze, some cities have implemented congestion charges to reduce traffic and the environmental pollution caused by it. Such cities include London, Stockholm, Gothenburg, and Singapore (Gopinath Menon and Kiankeong 2004). On February 17, 2003, the London Congestion Charging Scheme came into effect (Santos and Shaffer 2004). Subsequently, in-depth research was then performed, whose results revealed clearly that persons convinced of a definite introduction of road pricing developed more positive attitudes toward road pricing than less convinced persons (Schade and Baum 2007). Some researchers used the methods of cost-benefit analysis (Eliasson 2009) and comparative analysis to investigate the feasibility of the 
congestion charging strategy, and the positive experiences from the Stockholm congestion charges seemed to be transferable to other cities (Eliasson et al., 2013).In Gothenburg, experts also studied the effects, design of this policy and found that the introduction of congestion charges depended on the support by political parties (Borjesson and Kristoffersson 2015). Attitudes to congestion charges did indeed become more positive after this introduction, just as in previously mentioned cities (Borjesson et al. 2016). While such policies have reduced emissions in the short term, the long-term effects are not obvious. Using dynamic simulations, some studies in China have examined the effects of economic approaches such as fees and subsidies on traffic and its associated pollutants. For example, Jia et al. (2019) introduced the policy of vehicle pollution charging fees and, using simulations of different scenarios, revealed its rebound effect on vehicle trips as well as its turning-point effect; this provided theoretical support for implementing and improving the policy.

Regarding environmental policy and health impact, studies have explored the relationship between haze pollution, economic development, and public health. For example, Hao et al. (2018) estimated the effect of $\mathrm{PM}_{2.5}$ concentration on per capita GDP using 2013-2015 urban panel data. The results showed that haze pollution had a significant negative effect on the economy. It was suggested, therefore, that different green-technology policies should be formulated according to different geographical locations and industrial-structure characteristics, and economic investment and financial support should be increased to improve air quality. Chen and Chen (2018) examined the effect of environmental tax policies on industrial output and carbonemission reduction in the short and long term. They proposed that levying environmental taxes should be combined with other policies, such as tax preference or reduction and redistribution measures for tax revenues. Meanwhile, Zhu et al. (2020) found a strong relationship between air pollution and COVID-19 infection, which could have implications for controlling and preventing the disease. Cheung et al. (2020) found that air pollution led to higher cardiorespiratory mortality in Hong Kong. Sofia et al. (2020) used the method of cost-benefit analysis to assess the feasibility of the decarbonization scenario, applied in Italy in 2030. It provides important support to decision-makers.

In terms of administrative measures for controlling haze, some studies have examined implementing traffic restrictions to reduce congestion and control emissions (Xiao et al. 2019). While such policies can have positive shortterm effects, problems can arise in the long term, such as increased tension over parking spaces.

Regarding technical approaches to reducing emissions, methods such as installing gas-treatment equipment, improving oil quality, and raising emission standards have been considered (Wu et al. 2017). Researchers have also investigated pollution control in terms of subjective well-being (Li et al. 2018), vegetation cycle (Ottosen and Kumar 2020),
Fig. 1 Algorithm steps for the SD-EW-GM approach

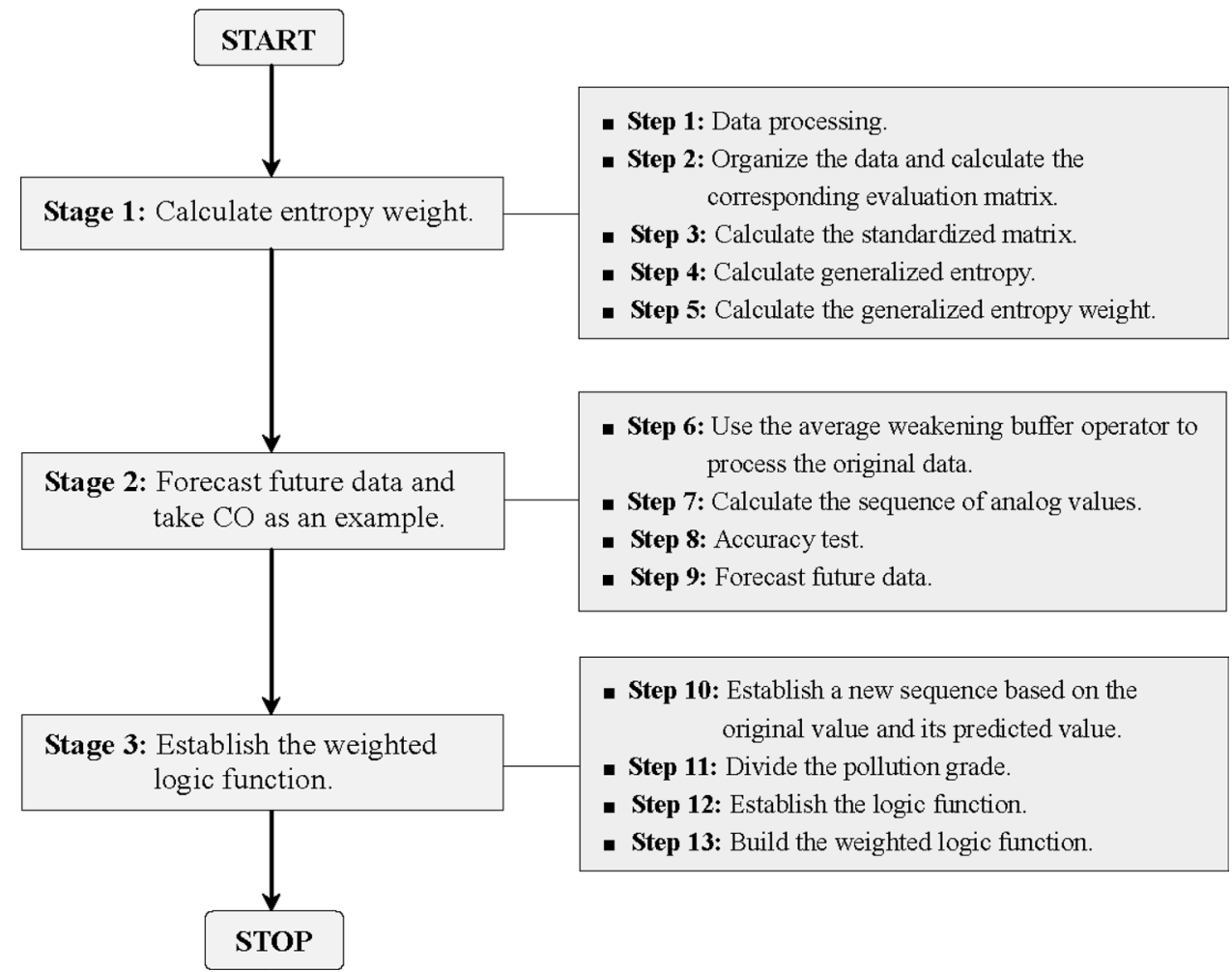


real-time on-road monitoring network (Lotrecchiano et al. 2019), the green paradox effect, and public opinion. Zhang et al. (2018), for example, studied air quality and government behavior in terms of the policy effect of public opinion. While public opinion was found to have a positive effect on improving air quality in the short term, the effect would gradually disappear in the long term.

The abovementioned studies have important reference value and significance for solving the problem of air pollution. However, there are still a number of problems. On the one hand, there is a lack of research on future trends. The existing research uses econometrics and other methods to analyze historical data while ignoring the future change trends of key factors. On the other hand, haze pollution continues to worsen year by year. The main reasons include the following: First, improved living standards and ongoing urbanization have increased the demand for cars, thereby increasing the total number of vehicles on the road. Second, due to a lack of restrictive measures, the proportion of motor vehicle travel remains high, showing a rapid growth trend. Third, unreasonable governance measures (e.g., restricting traffic and subsidizing new-energy vehicles) compel some car owners to buy additional vehicles, increasing the total number of motor vehicles.

The present study, therefore, took motor vehicles as an example to explore optimizing management and control strategies in terms of emission reduction, congestion alleviation, and health-impact improvement. First, a penalty mechanism and air pollution charging fee (APCF) are introduced to reduce motor vehicle trips, and the effects on reducing emissions and traffic congestion are shown. Second, this study adopted an integrated algorithm of system dynamics, entropy weight method, and gray system theory (SD-EW-GM) to optimize the existing management scheme for vehicle emission reduction. This will reduce the degree of air pollution and pollution losses, relieve traffic congestion, and increase citizen health index, contributing to multiple benefits, including economic, social, environmental, and health. More importantly, these new methods also provide a sound theoretical basis and decision-making reference for smart city development.

\section{Method and data collection}

\section{SD-EW-GM approach}

SD-EW-GM is an integrated algorithm that combines system dynamics (SD), the entropy weight method (EW), and gray system theory (GM). Taking the degree of air pollution caused by $\mathrm{CO}, \mathrm{HC}$, NOx, and PM emissions as an example, first calculate the emissions of different pollutants, and then calculate the corresponding pollution degree according to the actual air pollution situation. Second, the logical functions of four kinds of pollutants are constructed. Finally, the entropy weight method is used to calculate the different proportions and establish the weighted logic function. In this way, the integrated algorithm can more accurately describe air pollution caused by vehicle pollutants (see Fig. 1). The details are presented below.

Definition 1 (Zhang and Ren 2011). Assume that $A=\left(a_{i j}\right)_{m n}$ is the evaluation matrix of $m$ evaluation indexes and $n$ evaluation objects, and $A$ is standardized to get $A^{\prime}=\left(a_{i j}^{\prime}\right)_{m n}$, where $0 \leq a_{i j}^{\prime} \leq 1$. The entropy of the $i$ index is defined as $H_{i}$, and the corresponding entropy weight is $\omega_{i}$ :

$H_{i}=-k\left(p_{i 1} \ln p_{i 1}+p_{i 2} \ln p_{i 2}+\cdots+p_{i n} \ln p_{i n}\right)$,

where

$k=\frac{1}{\ln n}, \quad p_{i j}=\frac{a_{i j}^{\prime}+10^{-4}}{\sum_{j=1}^{n}\left(a_{i j}^{\prime}+10^{-4}\right)}$.

Then,

$\omega_{i}=\frac{1-H_{i}+\frac{1}{10} \sum_{i=1}^{m}\left(1-H_{i}\right)}{\sum_{l=1}^{m}\left|1-H_{i}+\frac{1}{10} \sum_{i=1}^{m}\left(1-H_{i}\right)\right|}$,

where

$0 \leq \omega_{i} \leq 1, \sum_{i=1}^{m} \omega_{i}=1, \quad(i=1,2, \ldots, m)$.

$H_{i}$ is called generalized entropy, and $\omega_{i}$ is called generalized entropy weight.

The larger the value of generalized entropy weight $\omega_{i}$, the larger the proportion of the $i$ index in the original data series, and vice versa.

\section{- Stage 1: Calculate entropy weight.}

\section{Step 1: Data processing.}

First, the original data are written as a sequence, marked as $X_{01}, X_{02}, \cdots, X_{0 m}$, where $X_{0 i}=\left(x_{0 i}(1), x_{0 i}(2), \cdots, x_{0 i}(n)\right)$, $i=1,2, \cdots, m$.

Second, use the operator $D_{1}$ to change the sequence $X_{0 i}$ into an isochronous sequence, which is recorded as $X_{1 i}$ :

$x_{1 i}(k) d_{1}=\frac{x_{0 i}\left(k_{n_{1}}\right)+x_{0 i}\left(k_{n_{2}}\right)}{2}$, 
where $k_{n_{1}}$ and $k_{n_{2}}$ have the same parity, and $k=\frac{k_{n_{1}}+k_{n_{2}}}{2}, n_{1} \in N^{+}, n_{2} \in N^{+}, 1 \leq k_{n_{1}}<k_{n_{2}} \leq n,(k=2,3, \cdots, n-1)$.

Third, the sequence $X_{1 i}$ is transformed into a one-time interval sequence, which is labeled $X_{i}, i=1,2, \cdots, m$.

Then,

$X_{1}=\left(x_{1}(1), x_{1}(2), \cdots, x_{1}(n)\right), \quad X_{2}=\left(x_{2}(1), x_{2}(2), \cdots\right.$,

$\left.x_{2}(n)\right), \cdots, X_{m}=\left(x_{m}(1), x_{m}(2), \cdots, x_{m}(n)\right)$,

where

$x_{i}(k)=\frac{x_{i}(k-1)+x_{i}(k+1)}{2}, i=1,2, \cdots, m$.

Step 2: Organize the data and calculate the corresponding evaluation matrix.

Based on sequence $X_{i}$, the evaluation matrix is obtained and marked $A$. Then,
$A=\left(X_{1}, X_{2}, \cdots, X_{m}\right)^{T}=\left[\begin{array}{cccc}x_{1}(1) & x_{1}(2) & \cdots & x_{1}(n) \\ x_{2}(1) & x_{2}(2) & \cdots & x_{2}(n) \\ \vdots & \vdots & & \vdots \\ x_{i}(1) & x_{i}(2) & \cdots & x_{i}(n) \\ \vdots & \vdots & & \vdots \\ x_{m}(1) & x_{m}(2) & \cdots & x_{m}(n)\end{array}\right]$.

\section{Step 3: Calculate the standardized matrix.}

Using the interval operator $D_{2}$ (Liu 2017) to standardize matrix $A$, obtained the standardized matrix

$A^{\prime}=\left[\begin{array}{cccc}x_{1}(1) d_{2} & x_{1}(2) d_{2} & \cdots & x_{1}(n) d_{2} \\ x_{2}(1) d_{2} & x_{2}(2) d_{2} & \cdots & x_{2}(n) d_{2} \\ \vdots & \vdots & & \vdots \\ x_{i}(1) d_{2} & x_{i}(2) d_{2} & \cdots & x_{i}(n) d_{2} \\ \vdots & \vdots & & \vdots \\ x_{m}(1) d_{2} & x_{m}(2) d_{2} & \cdots & x_{m}(n) d_{2}\end{array}\right]$

where

$$
x_{i}(k) d_{2}=\frac{x_{i}(k)-\min _{k}\left\{x_{i}(k)\right\}}{\max _{k}\left\{x_{i}(k)\right\}-\min _{k}\left\{x_{i}(k)\right\}}
$$

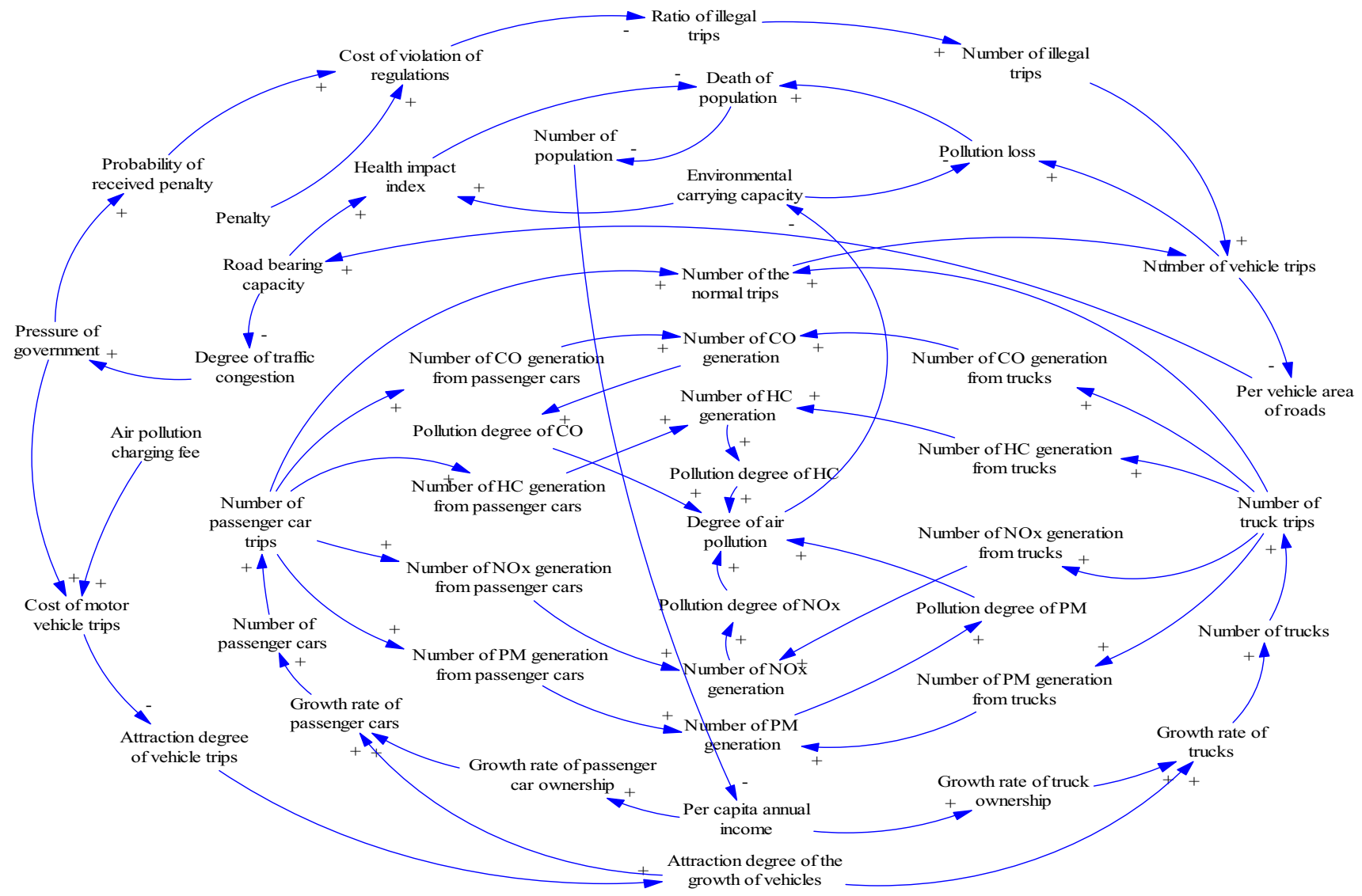

Fig. 2 Causal loop diagram of the vehicle pollutant control model 


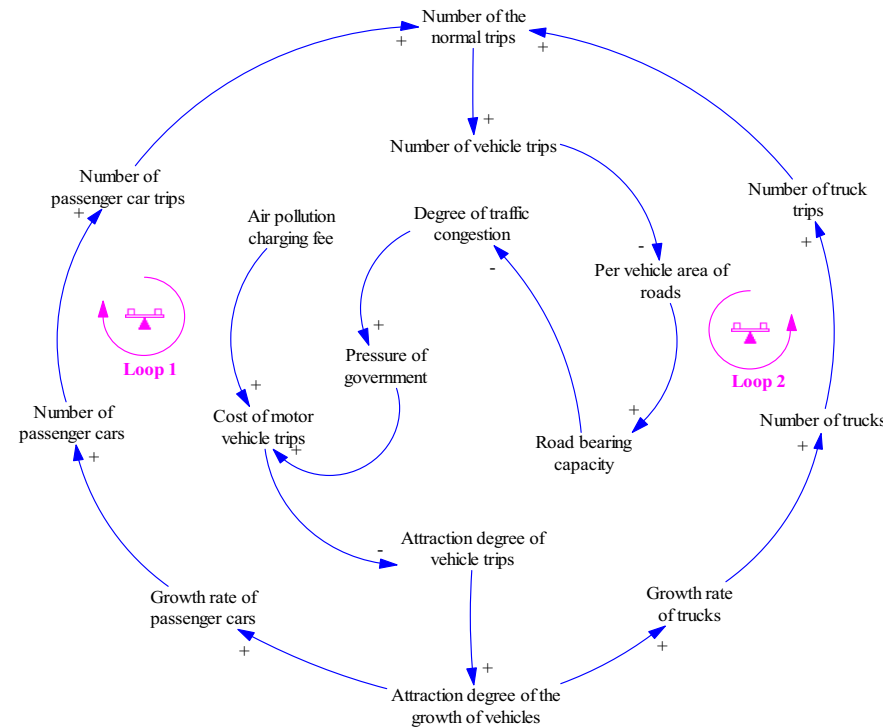

(a) Feedback loop of the degree of traffic congestion

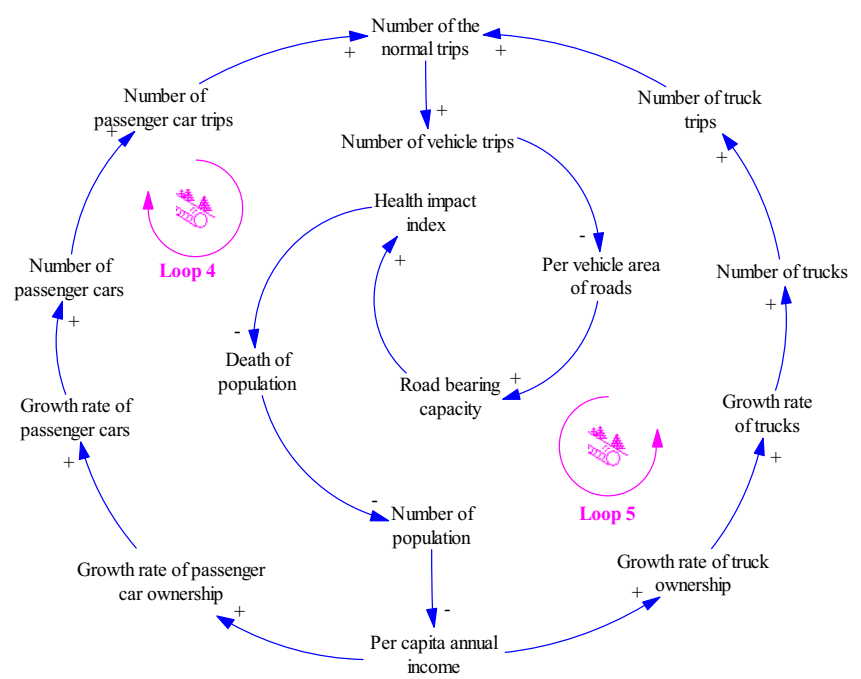

(c) Feedback loop of health impact index

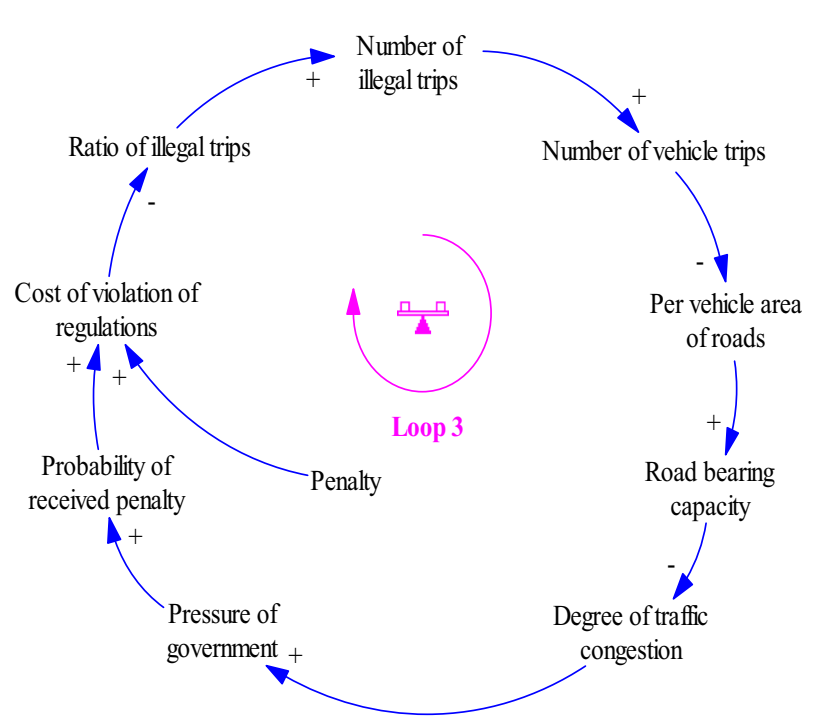

(b) Feedback loop of illegal trips

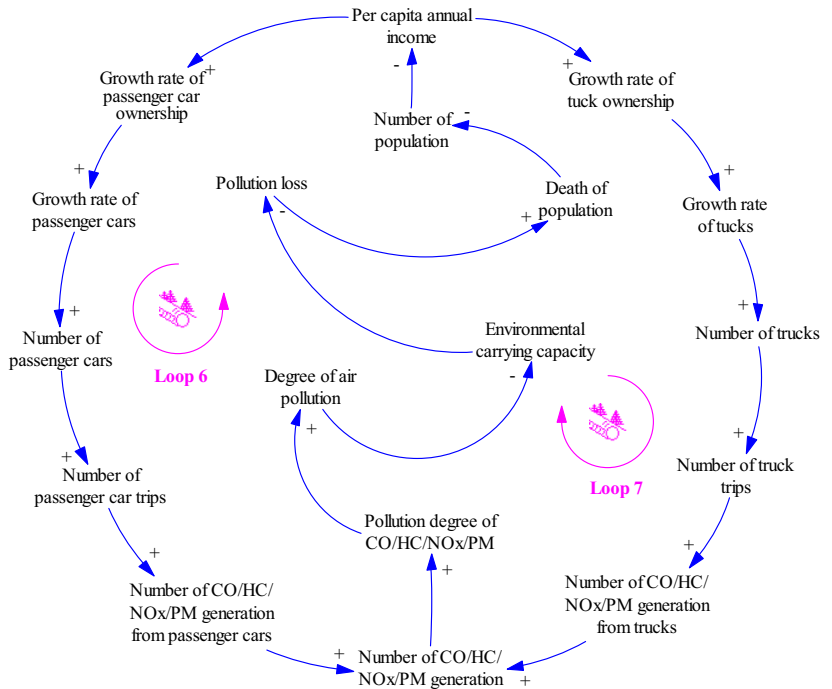

(d) Feedback loop of environmental carrying capacity

Fig. 3 The main feedback structure. a Feedback loop of the degree of traffic congestion; b feedback loop of illegal trips; $\mathbf{c}$ feedback loop of health impact index; $\mathbf{d}$ feedback loop of environmental carrying capacity

is denoted as $A^{\prime}=\left(a_{i j}^{\prime}\right)_{m \times n}$; then, $a_{i j}^{\prime} \in[0,1]$.

Step 4: Calculate generalized entropy.

Using Eqs. (1) and (2) to calculate generalized entropy $H_{i}$,

$H_{i}=-\frac{1}{\ln n} \sum_{j=1}^{n}\left(\frac{a_{i j}^{\prime}+10^{-4}}{\sum_{j=1}^{n}\left(a_{i j}^{\prime}+10^{-4}\right)} \cdot \ln \frac{a_{i j}^{\prime}+10^{-4}}{\sum_{j=1}^{n}\left(a_{i j}^{\prime}+10^{-4}\right)}\right)$,

where $i=1,2, \ldots, m ; j=1,2, \ldots, n$.

Step 5: Calculate the generalized entropy weight.
According to Eq. 3, we can obtain the generalized entropy weight of the $i$ index.

\section{- Stage 2: Forecast future data and take CO as an example.}

Step 6: Use the average weakening buffer operator to process the original data.

Introduce the second order operator of $D_{3}^{2}$ (Liu 2017); let 


$$
\begin{aligned}
X^{(0)} D_{3}^{2} & =\left(x^{(0)}(1) d_{3}^{2}, x^{(0)}(2) d_{3}^{2}, \ldots, x^{(0)}(N) d_{3}^{2}\right) \stackrel{\Delta}{=} X_{\mathrm{CO}} \\
& =\left(x_{\mathrm{CO}}(1), x_{\mathrm{CO}}(2), \ldots, x_{\mathrm{CO}}(N)\right),
\end{aligned}
$$

where

$x^{(0)}(k) d_{3}^{2}=\frac{1}{N-k+1}\left[x^{(0)}(k) d_{3}+x^{(0)}(k+1) d_{3}+\ldots+x^{(0)}(N) d_{3}\right]$

$x^{(0)}(k) d_{3}=\frac{1}{N-k+1}\left[x^{(0)}(k)+x^{(0)}(k+1)+\ldots+x^{(0)}(N)\right]$,

$k=1,2,3, \ldots, N$.

This operator can decrease the uncertainty in the original data, diminish or eliminate the impact disturbance on the system behavior data sequence, showing its regularity.

Then,

$X_{\mathrm{CO}}^{(0)}=\left(x_{\mathrm{CO}}^{(0)}(1), x_{\mathrm{CO}}^{(0)}(2), \cdots, x_{\mathrm{CO}}^{(0)}(N)\right)$.

Step 7: Calculate the sequence of analog values.

Use Model GM $(1,1)$ to calculate the sequence of analog values and obtain

$$
\left\{\begin{array}{l}
\hat{x}_{\mathrm{CO}}^{(1)}(k+1)=\left(x_{\mathrm{CO}}^{(0)}(1)-\frac{a}{b}\right) e^{-a k}+\frac{a}{b} \\
\hat{Y}(k+1)=\hat{x}_{\mathrm{CO}}^{(0)}(k+1)=\hat{x}_{\mathrm{CO}}^{(1)}(k+1)-\hat{x}_{\mathrm{CO}}^{(1)}(k), k=1,2, \ldots, N .
\end{array}\right.
$$

Step 8: Accuracy test.
Check whether the average relative error between the analog value sequence and the real value sequence is controlled within 5\%, where

$\varepsilon(k)=\left|\frac{x_{\mathrm{CO}}^{(0)}(k)-\hat{x}_{\mathrm{CO}}^{(0)}(k)}{x_{\mathrm{CO}}^{(0)}(k)}\right| \times 100 \%, \quad k=1,2, \ldots, N$.

$\bar{\varepsilon}=\frac{1}{N}(\varepsilon(1)+\varepsilon(2)+\cdots+\varepsilon(N))$.

\section{Step 9: Forecast future data.}

According to the results of step 8 , if $\bar{\varepsilon}<5 \%$, future data can be predicted and recorded as $\underset{\mathrm{CO}}{\hat{Y}}$,

$\hat{Y}_{\mathrm{CO}}=\left(y_{\mathrm{CO}}(N+1), y_{\mathrm{CO}}(N+2), y_{\mathrm{CO}}(N+3), \ldots, y_{\mathrm{CO}}(n)\right)$.

\section{- Stage 3: Establish the weighted logic function.}

Step 10: Establish a new sequence based on the original value and its predicted value.

The original value and the predicted value are combined into a new sequence and marked as $Y_{\mathrm{CO}}$. Then,

$Y_{\mathrm{CO}}=\left(x_{\mathrm{CO}}(1), x_{\mathrm{CO}}(2), \ldots, x_{\mathrm{CO}}(N)\right.$,

$$
\left.y_{\mathrm{CO}}(N+1), y_{\mathrm{CO}}(N+2), \ldots, y_{\mathrm{CO}}(n)\right) \text {. }
$$

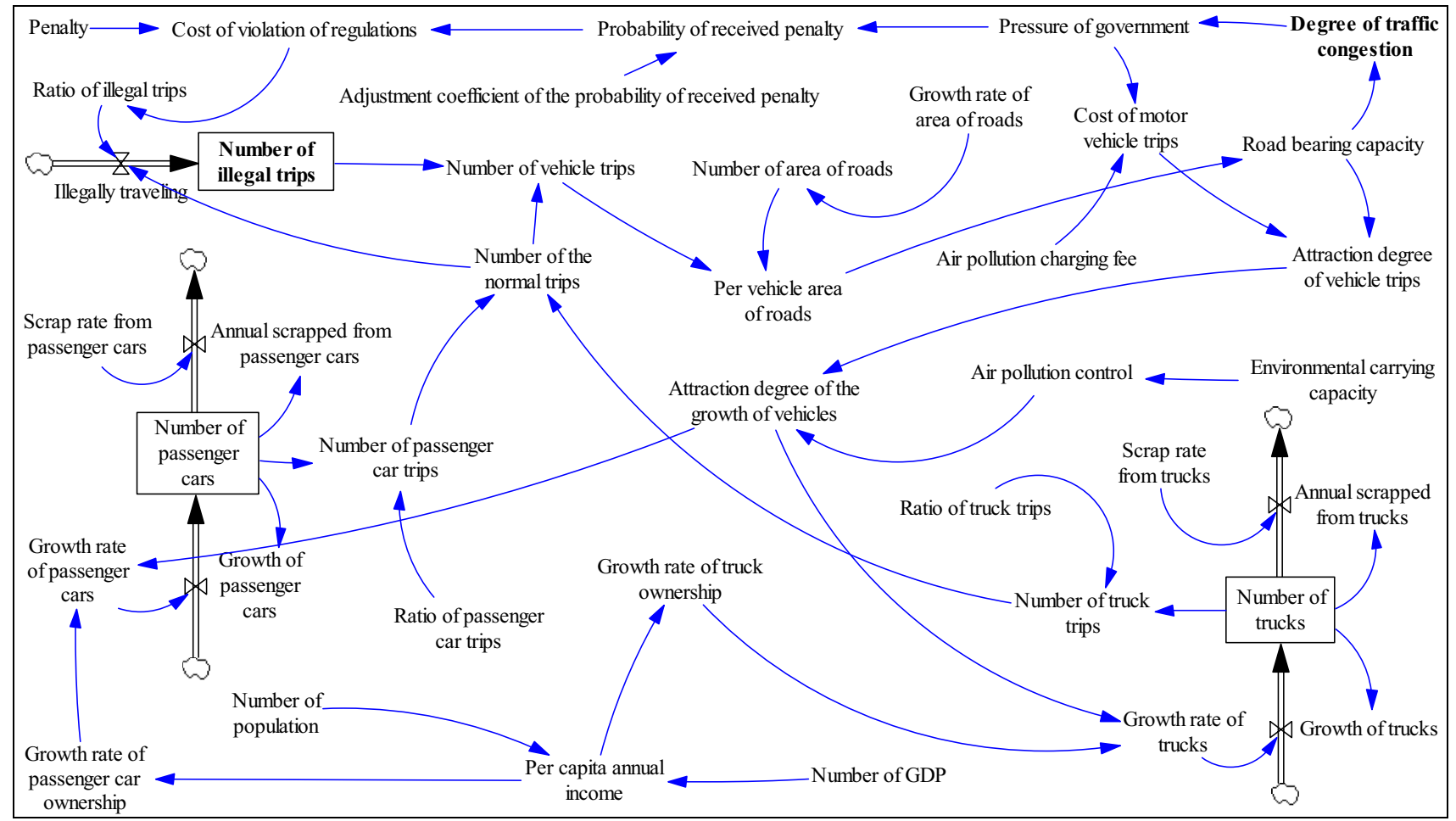

Fig. 4 Transport sub-model 


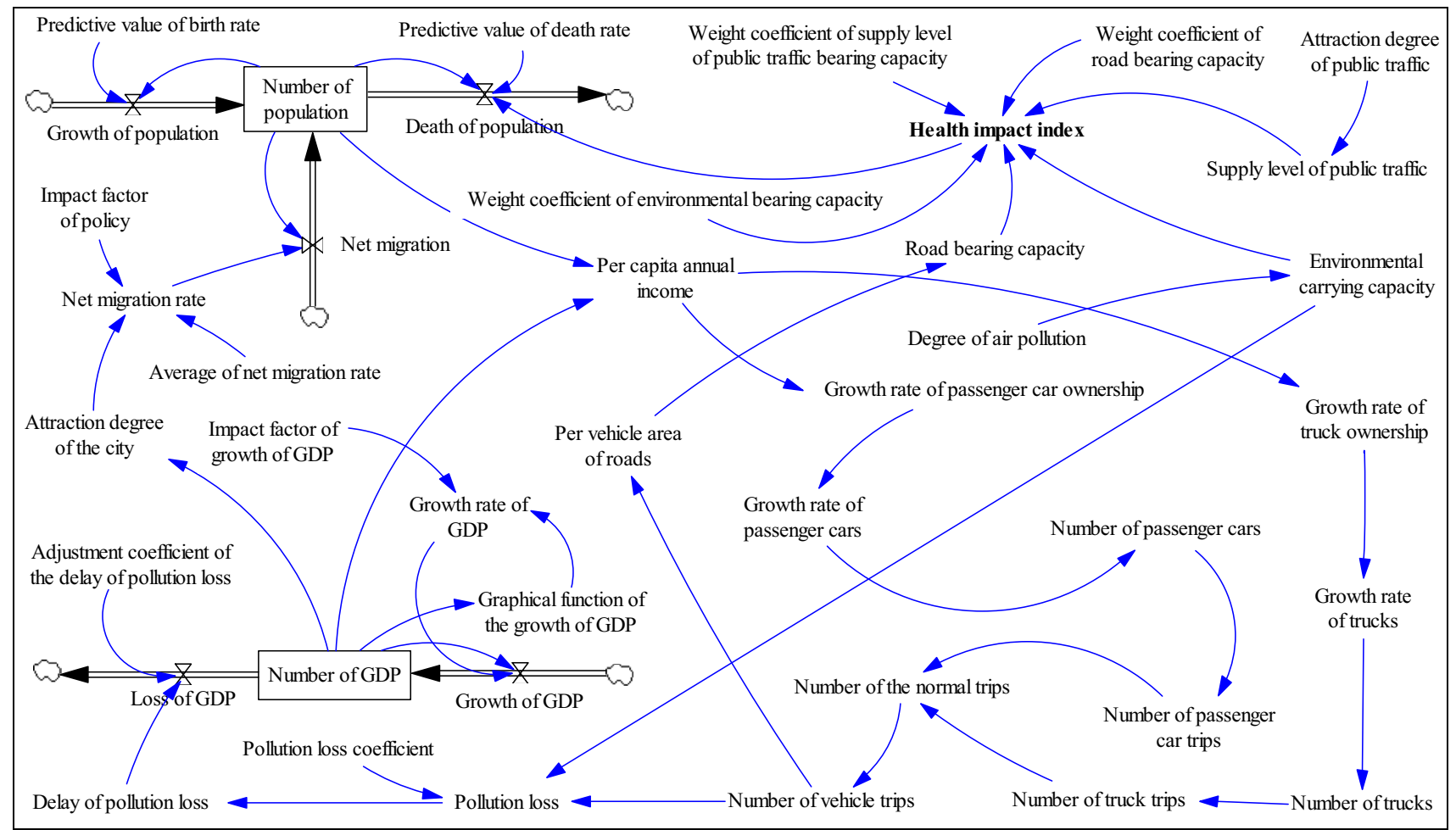

Fig. 5 Health sub-model

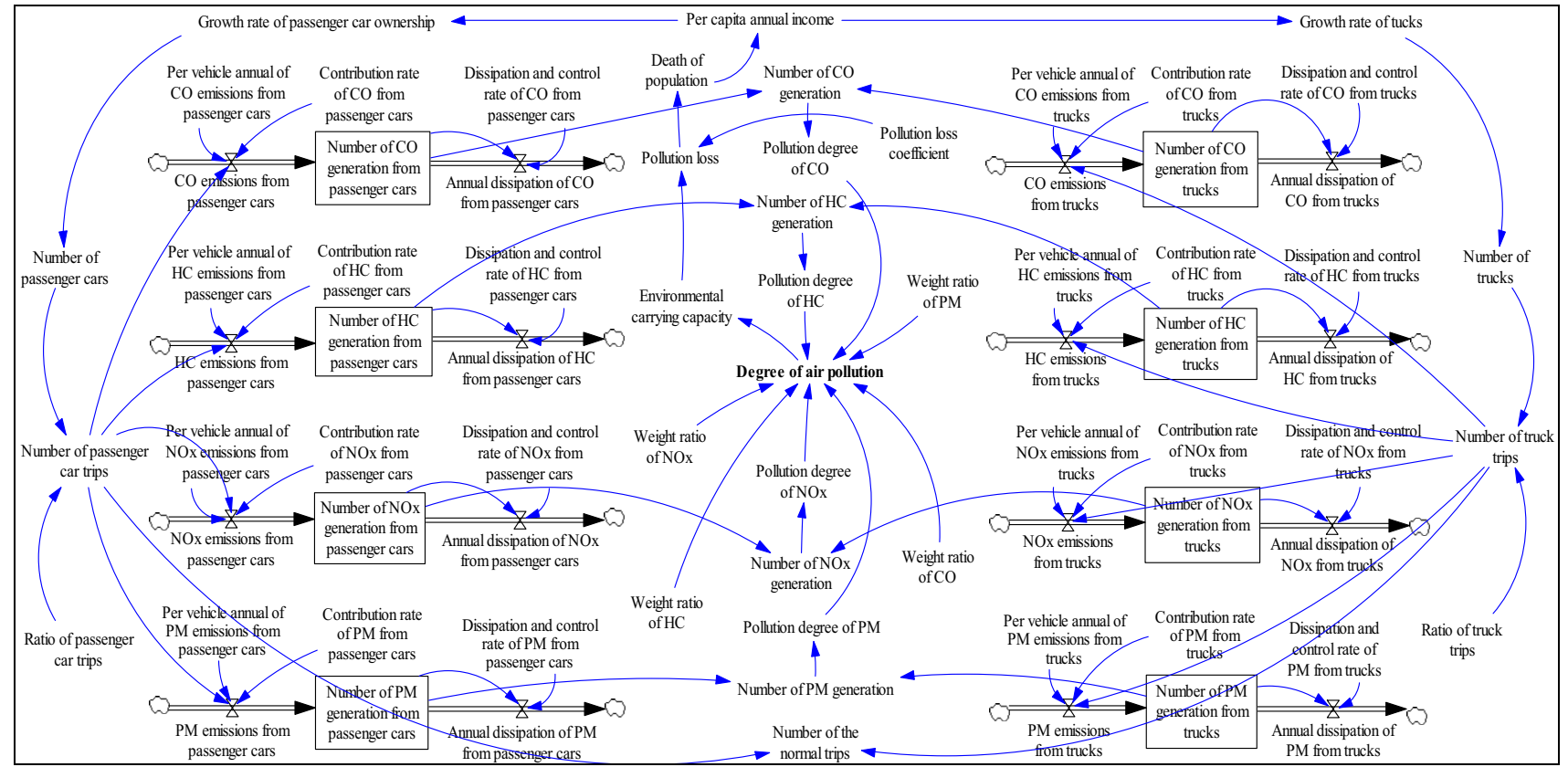

Fig. 6 Environmental sub-model

Step 11: Divide the pollution grade.

Assume the value range of the pollution degree is $0-1$. Then, $0.85-1$ is defined as serious pollution, and $0.7-0.85$, $0.5-0.7$, and $0.3-0.5$ are defined as heavy pollution, medium pollution, and light pollution, respectively. That is, $0.85<$ serious pollution $\leq 1.0,0.7<$ heavy pollution $\leq 0.85$, $0.5<$ medium pollution $\leq 0.7$, and $0.3<$ light pollution $\leq 0.5$. The values are assigned according to the actual air pollution. 
Table 1 Descriptions on the major sub-models

\begin{tabular}{|c|c|}
\hline Sub-model & Modeling purpose and key variables \\
\hline Transport sub-model & $\begin{array}{l}\text { The purpose of penalty policy in this sub-model is the reduction of the number of illegal trips. The following key } \\
\text { variables were used: number of passenger cars, number of trucks, road bearing capacity, number of illegal trips, } \\
\text { number of vehicle trips, degree of traffic congestion, etc. }\end{array}$ \\
\hline Health sub-model & $\begin{array}{l}\text { This sub-model aims to evaluate the health benefit of the combined APCF and penalty strategy. We implemented } \\
\text { the following key variables: health impact index, per vehicle area of roads, environmental carrying capacity, and } \\
\text { population death }\end{array}$ \\
\hline Environmental sub-model & $\begin{array}{l}\text { Using this sub-model, our main aim was to explore the emission reduction performance of the combined strategy. } \\
\text { The key variables included } C O / H C / N O x / P M \text { pollution degree, amount of } C O / H C / N O x / P M \text { generated by pas- } \\
\text { senger cars, and the degree of air pollution }\end{array}$ \\
\hline
\end{tabular}

Table 2 Main data information for road bearing capacity

\begin{tabular}{|c|c|c|c|c|c|c|c|}
\hline Time & $\begin{array}{l}\text { Number of area } \\
\text { of roads }\left(\mathrm{m}^{2}\right)\end{array}$ & $\begin{array}{l}\text { Number of } \\
\text { trucks (vehi- } \\
\text { cle) }\end{array}$ & $\begin{array}{l}\text { Number of passen- } \\
\text { ger cars (vehicle) }\end{array}$ & $\begin{array}{l}\text { Number of the nor- } \\
\text { mal trips (vehicle) }\end{array}$ & $\begin{array}{l}\text { Per vehicle area of } \\
\text { roads }\left(\mathrm{m}^{2} / \text { vehicle }\right)\end{array}$ & Degree of congestion & $\begin{array}{l}\text { Road bear- } \\
\text { ing capacity }\end{array}$ \\
\hline 2008 & $89,400,000$ & 181,000 & $2,910,000$ & $1,700,050$ & 52.587 & Mild & 0.6 \\
\hline 2009 & $91,790,000$ & 183,000 & $3,454,000$ & $2,000,350$ & 45.887 & Mild & 0.55 \\
\hline 2010 & $93,950,000$ & 194,000 & $4,257,000$ & $2,448,050$ & 38.377 & Mild & 0.5 \\
\hline 2011 & $91,640,000$ & 215,000 & $4,442,000$ & $2,561,350$ & 35.778 & Moderate & 0.45 \\
\hline 2012 & $92,360,000$ & 237,000 & $4,649,000$ & $2,687,300$ & 34.369 & Moderate & 0.25 \\
\hline 2013 & $96,110,000$ & 257,000 & $4,861,000$ & $2,814,900$ & 34.143 & Moderate & 0.2 \\
\hline 2014 & $100,020,000$ & 289,000 & $4,969,000$ & $2,891,900$ & 34.586 & Moderate & 0.4 \\
\hline 2015 & $100,290,000$ & 306000 & $4,981,000$ & $2,907,850$ & 34.489 & Moderate & 0.35 \\
\hline 2016 & $102,750,000$ & 330,000 & $5,094,000$ & $2,983,200$ & 34.443 & Moderate & 0.3 \\
\hline 2017 & $103,470,000$ & 367,000 & $5,208,000$ & $3,066,250$ & 33.745 & Serious & 0.15 \\
\hline 2018 & $103,280,000$ & 400,000 & $5,280,000$ & $3,124,000$ & 33.060 & Serious & 0.1 \\
\hline
\end{tabular}

\section{Step 12: Establish the logic function.}

According to step 11, use VENSIM software (Zhang et al. 2018) to establish the logic function and obtain the pollution degree of CO.

Repeat steps 6-11 and obtain the pollution degree of HC, pollution degree of NOx, and pollution degree of PM.

Step 13: Build the weighted logic function.

According to the calculation results of step 5 and step 12, we can calculate the degree of air pollution:

Degree of air pollution $=\omega_{\mathrm{CO}} \cdot$ Pollution degree of $\mathrm{CO}$

$+\omega_{\mathrm{HC}} \cdot$ Pollution degree of $\mathrm{HC}+\omega_{\mathrm{NOx}} \cdot$ Pollution degree of NOx

$+\omega_{P M} \cdot$ Pollution degree of PM

See "Appendix" for detailed calculation results.

\section{Causal loop diagram}

Focusing on traffic congestion and the associated air pollution in Beijing, this study introduced the APCF policy and penalty policy to establish a causal loop diagram, as shown in Fig. 2. It mainly includes seven feedback loops, as shown in Fig. 3.

Figure $3 \mathrm{a}$ is a feedback loop of the degree of traffic congestion; it includes loop 1 and loop 2, both of which are negative feedback loops. In loop 1, for example, the increasing degree of traffic congestion increases governance pressure, which will increase the cost of motor vehicle travel. Increased motor vehicle travel cost will reduce the attraction degree of vehicle trips, the attraction degree of vehicle growth, the growth rate of passenger cars, the number of passenger cars, the number of normal trips, and the number of vehicle trips. Reducing the number of vehicle trips will increase the per vehicle area of roads, thus improving road bearing capacity and ultimately reducing traffic congestion. The APCF policy can further increase the cost of motor vehicle trips and ultimately reduce the degree of traffic congestion. The analysis of loop 2 is similar.

Figure $3 b$ is the feedback loop of illegal trips. Loop 3 is a negative feedback loop, which aims to increase the cost of regulation violation through the penalty policy to reduce the number of illegal trips. 
Figure $3 c$ is the feedback loop of the health impact index. It contains two positive feedback loops (loop 4 and loop 5). In loop 4, for example, increasing the health impact index will reduce deaths, thus increasing the population and reducing per capita annual income. The decline in per capita annual income will reduce the growth rate of passenger cars, thus reducing the number of passenger cars and trips. This will increase the per vehicle area of roads and enhance road bearing capacity. To some extent, improving road bearing capacity can increase the health impact index.

Figure $3 \mathrm{~d}$ is the feedback loop of environmental carrying capacity; loops 6 and 7 are both positive feedback loops. In loop 6, for example, improving environmental carrying capacity can reduce pollution to some extent and further reduce deaths. Per capita GDP decreases accordingly, which eases the growth rate of passenger cars and to some extent reduces the number of passenger car trips. Such reduction can decrease $\mathrm{CO} / \mathrm{HC} / \mathrm{NO} / \mathrm{PM}$ generation and thus decrease air pollution, which will improve environmental carrying capacity. Therefore, at first, the improvement of environmental bearing capacity, after the role of this loop, it will eventually be further improved.

\section{Flow diagram}

Based on the causal loop analysis in "Causal loop diagram" section, the corresponding flow diagram can be obtained. It mainly includes the transport subsystem, health subsystem, and environmental subsystem, as shown in Figs. 4, 5 and 6 and Table 1.

\section{Transport subsystem}

In the transport subsystem (Fig. 4), the APCF policy is introduced to reduce the degree of traffic congestion, and the penalty policy is introduced to decrease the number of illegal trips. Based on the China Mobile Source Environmental Management Annual Report (2019), China Vehicle Environmental Management Annual Report (2016-2018), China Vehicle Emission Control Annual Report (2011-2015), Beijing Statistical Yearbook (2009-2019), and China Statistical Yearbook (2009-2019), the following equations can be obtained:

Number of passenger cars $=$ INTEG (growth of passenger cars - annual scrapped passenger cars, $4.442 \mathrm{e}+006)$.

Number of trucks $=$ INTEG $($ growth of trucks

- annual scrapped from trucks, 215, 000).

Number of illegal trips = INTEG (illegal trips, 0).

Road bearing capacity = WITH LOOKUP (per vehicle area of roads, $([(20,0)-(100,1)],(30,0.05),(33.06,0.1),(33.745,0.15)$, $(34.143,0.2), \quad(34.369,0.25),(34.443,0.3),(34.489,0.35)$, $(34.586,0.4),(35.778,0.45), \quad(38.377,0.5),(45.887,0.55)$, $(52.587,0.6),(60,0.65),(80,0.8),(100,0.9)))$.

Equations (12)-(14) are all level variables, their initial values are 4.442e+006, 215,000, and 0, respectively. Equation (15) is determined from Table 2. In Table 2, first, the per vehicle area of roads according to the area of roads, number of trucks, and number of passenger cars is calculated.

Second, combined with the actual situation of Beijing each year, the values are assigned. Finally, VENSIM is used to establish the graphical function.

The following parameters can be determined by referring to the literature (Zhu 2013).

Scrap rate from passenger cars $=0.067$. (a) Pollution loss

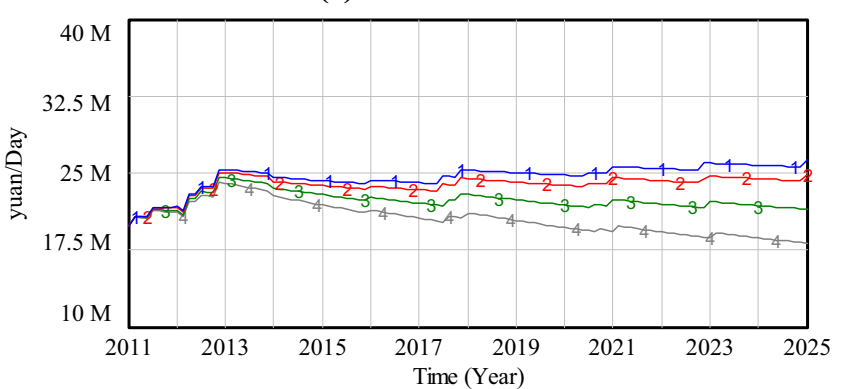

"(a) Pollution loss" : Penalty=5 $\quad 1 \quad 1 \quad \begin{array}{lllllll}1 & 1 & 1 & 1 & 1 & 1 & 1\end{array}$

"(a) Pollution loss" : Penalty=500 $\begin{array}{lllllll}2 & 2 & 2 & 2 & 2 & 2\end{array}$

"(a) Pollution loss" : Penalty=1000 $33 \quad 3 \quad \begin{array}{llllll}10 & 3 & 3 & 3 & 3\end{array}$

"(a) Pollution loss" : Penalty $=5000$ (b) Road bearing capacity

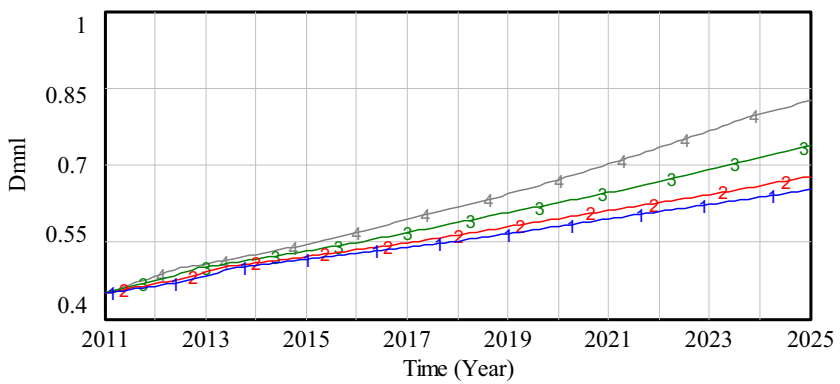

"(b) Road bearing capacity" : Penalty $=5 \quad \begin{array}{lllllll}1 & 1 & 1 & 1 & 1 & 1\end{array}$ "(b) Road bearing capacity" : Penalty $=500 \begin{array}{lllllll}2 & 2 & 2 & 2 & 2 & 2\end{array}$

"(b) Road bearing capacity" : Penalty $=1000$

"(b) Road bearing capacity" : Penalty $=5000$

Fig. 7 Extreme condition test. a Pollution loss; $\mathbf{b}$ road bearing capacity 
Ratio of passenger car trips $=0.55$.

Scrap rate from trucks $=0.067$.

\section{Health subsystem}

In the health subsystem (Fig. 5), road bearing capacity and environmental carrying capacity are improved through APCF and penalty policies, and then health impact index (HII) is improved. Based on the Beijing Statistical Yearbook (2009), the following equations can be obtained:

Number of population $=$ INTEG $($ growth of population + net migration - death of population, 2.0186e + 007).

\section{Number of GDP $=$ INTEG $($ growth of GDP}

- loss of GDP, 1.66279e + 012).

Health impact index $=$ environmental carrying capacity

* weight coefficient of environmental bearingcapacity

+ supply level of public traffic $*$ weight coefficient of

supply level of public traffic bearing capacity

+ road bearing capacity $*$ weight coefficient of

road bearing capacity.

Among these, Eqs. (19)-(20) are all level variables, with initial values of $2.0186 \mathrm{e}+007$ and $1.66279 \mathrm{e}+012$, respectively. Equation (21) is jointly determined by environmental carrying capacity, supply level of public traffic, and road bearing capacity.

\section{Environmental subsystem}

In the environmental subsystem (Fig. 6), reduce the degree of air pollution by using the vehicle emission reduction strategy to improve environmental carrying capacity and reduce pollution loss. The following are the typical equations:

$$
\begin{aligned}
\text { Pollution degree of CO }=\text { IF THEN ELSE(Number of CO generation } \\
>=878502.9848,0.95, \text { IF THENELSE(Number of CO generation } \\
>=871878.6055,0.94, \text { IF THEN ELSE(Number of CO generation } \\
>=865304.1775,0.93, \text { IF THEN ELSE(Number of CO generation } \\
>=858779.3242,0.92, \text { IF THENELSE(Number of CO generation } \\
>=852303.6717,0.91, \text { IF THEN ELSE(Number of CO generation } \\
>=845876.8491,0.9, \text { IF THEN ELSE(Number of CO generation } \\
>=839498.4881,0.88, \text { IF THENELSE(Number of CO generation } \\
>=833128,0.85, \text { IF THEN ELSE(Number of CO generation } \\
>=809699.5,0.8, \text { IF THEN ELSE(Number of CO generation } \\
>=779285.4,0.75, \text { IF THEN ELSE(Number of COgeneration } \\
>=754691.2,0.7, \text { IF THEN ELSE(Number of CO generation } \\
>=745748.3,0.65, \text { IF THENELSE(Number of CO generation } \\
>=718272.3,0.6, \text { IF THEN ELSE(Number of CO generation } \\
>=683095.1,0.55, \text { IF THEN ELSE(Number of CO generation } \\
>=647664.7,0.5, \text { IF THEN ELSE(Number of COgeneration } \\
>=615413.6,0.45, \text { IF THEN ELSE(Number of CO generation } \\
>=510540.7,0.35, \text { IF THENELSE(Number of CO generation } \\
>=441882.1,0.3,0.2)))))))))))))))))
\end{aligned}
$$

\begin{tabular}{|c|c|c|c|c|c|c|}
\hline \multirow[t]{2}{*}{ Year } & \multicolumn{3}{|c|}{ Number of GDP (yuan) } & \multicolumn{3}{|c|}{ Number of population (person) } \\
\hline & Historical value & Simulated value & $\begin{array}{l}\text { Relative } \\
\text { error }(\%)\end{array}$ & Historical value & Simulated value & $\begin{array}{l}\text { Relative } \\
\text { error (\%) }\end{array}$ \\
\hline 2011 & $1.66279 \mathrm{e}+012$ & $1.66279 \mathrm{e}+012$ & - & $2.0186 \mathrm{e}+007$ & $2.01860 \mathrm{e}+007$ & - \\
\hline 2012 & $1.83501 \mathrm{e}+012$ & $1.87403 \mathrm{e}+012$ & 2.13 & $2.0693 e+007$ & $2.02354 \mathrm{e}+007$ & 2.21 \\
\hline 2013 & $2.03301 \mathrm{e}+012$ & $2.07420 \mathrm{e}+012$ & 2.03 & $2.1148 \mathrm{e}+007$ & $2.02933 e+007$ & 4.04 \\
\hline 2014 & $2.19441 \mathrm{e}+012$ & $2.25459 \mathrm{e}+012$ & 2.74 & $2.1516 \mathrm{e}+007$ & $2.03582 \mathrm{e}+007$ & 5.38 \\
\hline 2015 & $2.36857 \mathrm{e}+012$ & $2.43231 \mathrm{e}+012$ & 2.69 & $2.1705 e+007$ & $2.04249 \mathrm{e}+007$ & 5.90 \\
\hline 2016 & $2.56691 \mathrm{e}+012$ & $2.63295 \mathrm{e}+012$ & 2.57 & $2.1729 \mathrm{e}+007$ & $2.04947 \mathrm{e}+007$ & 5.68 \\
\hline 2017 & $2.80149 \mathrm{e}+012$ & $2.84815 \mathrm{e}+012$ & 1.67 & $2.1707 e+007$ & $2.05688 \mathrm{e}+007$ & 5.24 \\
\hline 2018 & $3.03200 \mathrm{e}+012$ & $2.90148 \mathrm{e}+012$ & 4.30 & $2.1542 \mathrm{e}+007$ & $2.06470 \mathrm{e}+007$ & 4.15 \\
\hline
\end{tabular}

Weight ratio of $\mathrm{CO}=0.23500$.

Weight ratio of $\mathrm{HC}=0.23922$.

Weight ratio of NOx $=0.25952$.

Weight ratio of $\mathrm{PM}=0.26626$.
Table 3 Model validation 
(a)

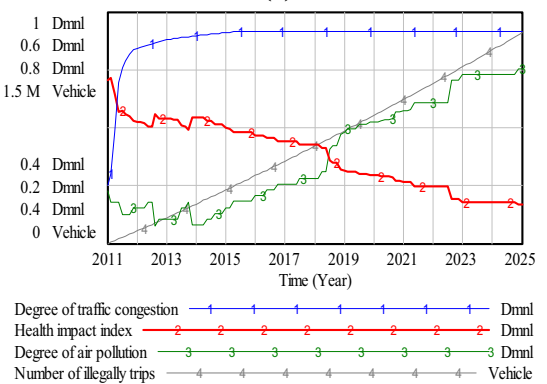

(d)

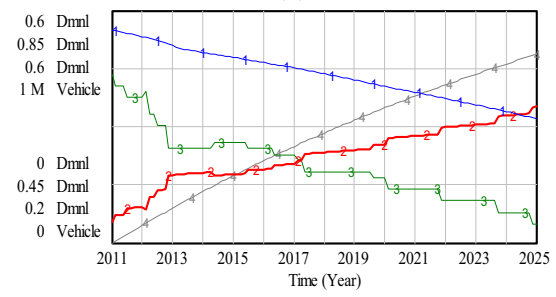

Degree of traffic congestion $1,1,1,1,1,1-$ Dml

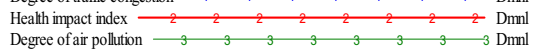
Number of illegally trips

(g)

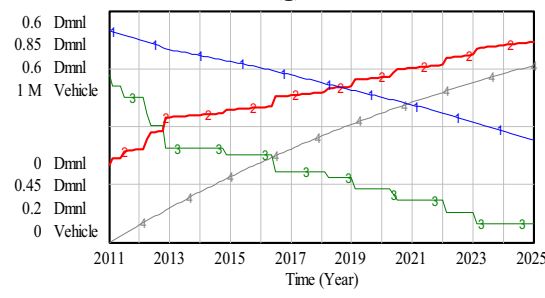

Degree of traffic congestion $1,1,1,1,1,1,1$ Dmnl Health impact index
Degree of air pollution Number of illegally trips (b)

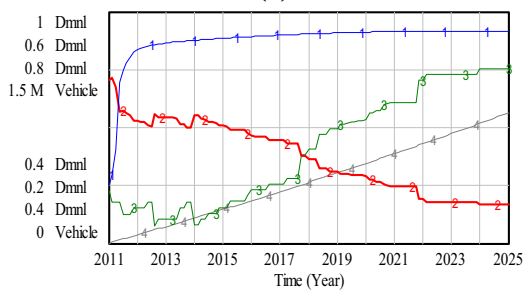

Degree of traffic congestion $1,1,1,1,1,1,1-\mathrm{Dmm}$

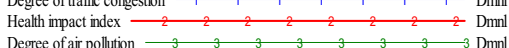

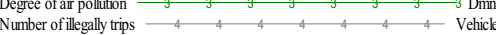

(e)
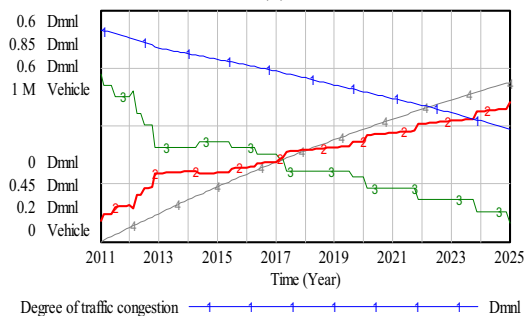

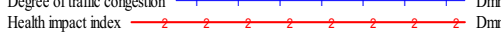

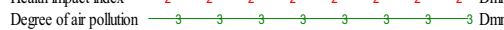
Number of illegally trips $-\begin{array}{lllllllll}4 & 4 & 4 & 4 & 4 & 4 & 4 & \text { Vehicl }\end{array}$

(h)

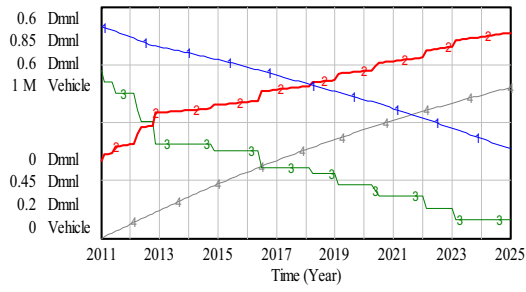

Degree of traffic congestion $1,1,1,1,1,1,1$ Dmm

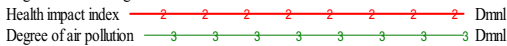

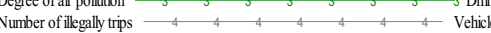

(c)

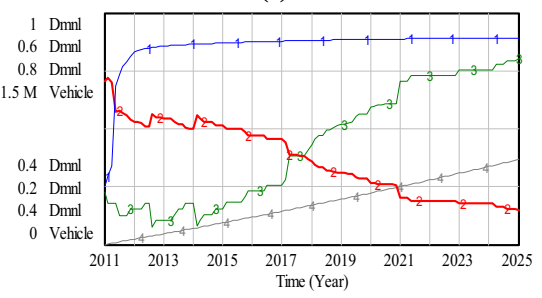

Degree of traffic congestion $1,1,1,1,1$ 1 Dmnl

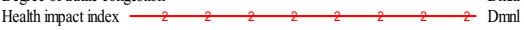
Degree of air pollution $\begin{array}{lllllllll}3 & 3 & 3 & 3 & 3 & 3 & 3 & 3\end{array}$ Dmnl Number of illegally trips $\begin{array}{cccccccc}4 & 4 & 4 & 4 & 4 & 4 & 4 & \text { Vehicle }\end{array}$

(f)

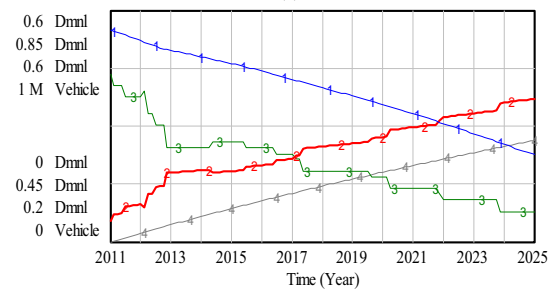

Degree of traffic congestion $1,1,1,1,1,1$ Dml

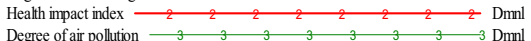
Number of illegally trips

(i)

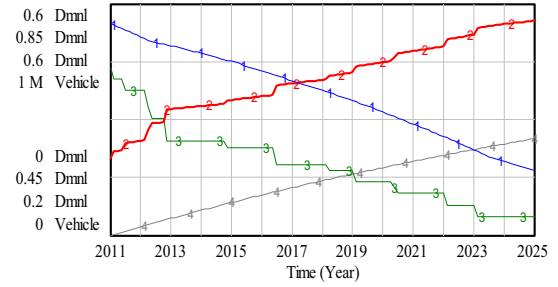

Degree of traffic congestion $+1,1,1,1,1$, Dml

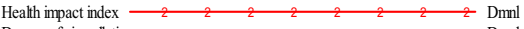
Degree of air pollution $\begin{array}{llllllll}3 & 3 & 3 & 3 & 3 & 3 & 3 & 3\end{array}$ Dml Number of illegally trips $\begin{array}{lllllllllll}4 & 4 & 4 & 4 & 4 & 4 & 4 & \text { Vehicle }\end{array}$

Fig. 8 Threefold effect of the combined scenario of the penalty and APCF. a Scenario 1: $\left(A_{L}, P_{L}\right)$; b scenario 2: $\left(A_{L}, P_{M}\right) ; \mathbf{c}$ scenario 3: $\left(A_{L}, P_{H}\right)$; d scenario 4: $\left(\mathrm{A}_{\mathrm{M}}, \mathrm{P}_{\mathrm{L}}\right)$; e scenario 5: $\left(\mathrm{A}_{\mathrm{M}}, \mathrm{P}_{\mathrm{M}}\right)$; f scenario 6: $\left(\mathrm{A}_{\mathrm{M}}, \mathrm{P}_{\mathrm{H}}\right) ; \mathbf{g}$ scenario 7: $\left(\mathrm{A}_{\mathrm{H}}, \mathrm{P}_{\mathrm{L}}\right) ; \mathbf{h}$ scenario 8: $\left(\mathrm{A}_{\mathrm{H}}, \mathrm{P}_{\mathrm{M}}\right) ; \mathbf{i}$ scenario 9: $\left(\mathrm{A}_{\mathrm{H}}, \mathrm{P}_{\mathrm{H}}\right)$

Table 4 The effect of the major variables under different scenarios

\begin{tabular}{lllll}
\hline Variable & Scenario 1 & Scenario 5 & Scenario 9 & Rate of change (\%) \\
\hline Degree of traffic congestion & 0.95 & 0.2922 & 0.1672 & -82.40 \\
Health impact index & 0.2298 & 0.6876 & 0.8710 & 279.03 \\
Degree of air pollution & 0.7683 & 0.2389 & 0.2389 & -68.91 \\
Number of illegally trips (vehicle) & $1,363,030$ & 687,515 & 417,814 & -69.35 \\
\hline
\end{tabular}

Degree of air pollution $=$ weight ratio of $\mathrm{CO} *$ pollution degree of $\mathrm{CO}$

+ weight ratio of $\mathrm{HC} *$ pollution degree of $\mathrm{HC}+$ weight ratio of $\mathrm{NOx}$

* pollution degree of NOx + weight ratio of $\mathrm{PM} *$ pollution degree of PM.

Number of $\mathrm{CO}$ generation from passenger cars

= INTEG (CO emissions from passenger cars

- annual dissipation of CO from passenger cars, 553, 473)
Number of $\mathrm{CO}$ generation from trucks

$=$ INTEG $(\mathrm{CO}$ emissions from trucks

- annual dissipation of CO from trucks, 94191.5).

Among these, Eqs. (28) and (29) are obtained based on the Beijing Statistical Yearbook (2009); Eqs. (22)-(27) can be obtained according to "SD-EW-GM approach" section. See "Appendix" for the detailed results. 


\section{Results}

\section{Scenario design}

In this section, penalty and APCF policy are divided into three types: low, moderate, and high. Nine scenarios are designed to analyze dynamic changes in the main variables through long-term simulation.

Simulation period: $2011-2025$. Time step $=1$, and the unit of time is year.

Let population number were approximately $2.27 \%$ and $4.01 \%$, respectively. Hence, the average relative error was within the controllable range.

\section{Results and discussion}

The key variables of the degree of traffic congestion (transport sub-model), health impact index (health sub-model), degree of air pollution (environmental sub-model), and number of illegal trips (transport sub-model) are selected to explore the threefold effect (such as Economic, environ-

$\left[\begin{array}{c}\text { Low - APCF } \\ \text { Moderate - APCF } \\ \text { High - APCF }\end{array}\right]=\left[\begin{array}{c}A_{\mathrm{L}} \\ A_{\mathrm{M}} \\ A_{\mathrm{H}}\end{array}\right]=\left[\begin{array}{c}1 \\ 10 \\ 100\end{array}\right],\left[\begin{array}{c}\text { Low - penalty } \\ \text { Moderate - penalty } \\ \text { High - penalty }\end{array}\right]=\left[\begin{array}{c}P_{\mathrm{L}} \\ P_{\mathrm{M}} \\ P_{\mathrm{H}}\end{array}\right]=\left[\begin{array}{c}50 \\ 500 \\ 1000\end{array}\right]$

So,

$\left[\begin{array}{c}\text { Scenario1 } \\ \text { Scenario2 } \\ \text { Scenario3 } \\ \vdots \\ \text { Scenario9 }\end{array}\right]=\left[\begin{array}{c}\left(A_{\mathrm{L}}, P_{\mathrm{L}}\right) \\ \left(A_{\mathrm{L}}, P_{\mathrm{M}}\right) \\ \left(A_{\mathrm{L}}, P_{\mathrm{H}}\right) \\ \left(A_{\mathrm{M}}, P_{\mathrm{L}}\right) \\ \left(A_{\mathrm{M}}, P_{\mathrm{M}}\right) \\ \left(A_{\mathrm{M}}, P_{\mathrm{H}}\right) \\ \left(A_{\mathrm{H}}, P_{\mathrm{L}}\right) \\ \left(A_{\mathrm{H}}, P_{\mathrm{M}}\right) \\ \left(A_{\mathrm{H}}, P_{\mathrm{H}}\right)\end{array}\right]=\left[\begin{array}{c}(1,50) \\ (1,500) \\ (1,1000) \\ (10,50) \\ (10,500) \\ (10,1000) \\ (100,50) \\ (100,500) \\ (100,1000)\end{array}\right]$.

\section{Model test and validation}

Here, the extreme condition test is taken as an example to conduct the model test; Fig. 7 shows the detailed results.

As shown in Fig. 7a, when the penalty is equal to the extreme value of 5, the value of pollution loss is the largest. This shows that under the effect of the low penalty policy, the number of illegal trips and vehicle trips still rises, and finally pollution loss shows a slow growth trend. With the increase of the penalty, pollution loss decreases. In particular, when the penalty is equal to the extreme value of 5000 , the reduction of pollution loss is the most significant. Figure $7 \mathrm{~b}$ shows that with the growth of the penalty, the number of illegal trips decreases continuously, thus increasing the per vehicle area of roads to some extent, and finally road bearing capacity shows a rising trend. These results show that the model can reflect the role of the penalty policy and has a certain robustness.

Table 3 shows the average relative error between the simulated value and the historical value. Our calculation results showed that the average relative errors in the GDP value and mental, and health benefit) of the combined strategy. The simulation results are shown in Fig. 8.

\section{Horizontal analysis}

$a \rightarrow b \rightarrow c ; d \rightarrow e \rightarrow f ; g \rightarrow h \rightarrow i$.

With the increase of the penalty, the changes in curves 1-4 have different effects on emission reduction, traffic congestion alleviation, and health impact index improvement. Curve 4 shows the most significant change while the changes in curves 1-3 are not obvious. In particular, from Fig. 8a-c, curves 1 and 3 still show an upward trend, and the health impact index shows a rapid downward trend. These results indicate that the penalty policy can effectively inhibit the growth of the number of illegal trips. However, the effects on emission reduction and congestion alleviation are very limited. Among them, under the low-APCF policy, the effects are the least obvious.

\section{Longitudinal analysis}

$a \rightarrow d \rightarrow g ; b \rightarrow e \rightarrow h ; c \rightarrow f \rightarrow i$.

With increased APCF, curve 1 and curve 3 decrease significantly while curve 2 and curve 4 change to some extent. This shows that the APCF policy can not only effectively alleviate congestion and reduce emissions but also improve the health impact index. In addition, it also has a positive effect on the number of illegal trips. Therefore, the APCF policy brings a double dividend effect, especially in terms of social and environmental benefits.

\section{Diagonal analysis}

$a \rightarrow e \rightarrow i$. 
With increases in the penalty and APCF, curves 1-4 change significantly. Table 4 indicates that curve 1 decreases from 0.95 to 0.1672 - a decrease of $82.4 \%$. Curve 4 decreases from 1,363,030 to 417,814-a decrease of $69.35 \%$. These results demonstrate that the significant effect of scenario 9 is the alleviation of traffic congestion. Curve 2 increases from 0.2298 to 0.8710 - an increase of about $279.03 \%$-reflecting the positive role of scenario 9 in improving the health impact index. Curve 3 decreases from 0.7683 to 0.2389 (about $68.91 \%$ ), indicating that this scenario has good environmental performance.

From the above analysis, we can see that the highpenalty policy has an obvious inhibitory effect on illegal motor vehicle trips (Fig. 8a-c). Therefore, to ensure the effectiveness of the policy, management and punishment should be strengthened. The APCF policy mainly serves to alleviate traffic congestion (curve 1 in Fig. 8a, c, d) and reduce the degree of air pollution (curve 3 in Fig. 8a, c, d). The high-penalty and high-APCF policy fully integrates the advantages of the two strategies and has a threefold effect. It not only reduces the degree of air pollution (curve 3 in Fig. 8a, i) and relieves traffic congestion (curves 1 and 4 in Fig. 8a, i) but also effectively improves the health impact index (curve 2 in Fig. 8a, i). Hence, this combined strategy can be regarded as collaborative innovation.

\section{Conclusions and policy recommendations}

\section{Main conclusions}

Focusing on urban traffic congestion and the corresponding haze pollution, this study took motor vehicles as an example and used an integrated algorithm to establish a control model for vehicle pollutant emission reduction. Based on causal analysis and simulation analysis, the following conclusions are obtained.

The weighted logic function algorithm based on the integrated SD-EW-GM fully absorbs the advantages of system dynamics and gray system theory; it can determine the parameters and equations with nonlinear characteristics and a lack of data information. A new method of system dynamics modeling and simulation is thereby proposed. The medium- and long-term dynamic simulation explored the future development trends of key factors and then provided new ideas for the optimization of policy programs.

Meanwhile, the combined penalty and APCF policy have a threefold effect. Although the penalty policy alone can effectively inhibit illegal trips $(\sim 59.61 \%)$, its effect on emission reduction $(\sim 2.97 \%)$ and congestion alleviation $(\sim 1.61 \%)$ is limited. The APCF policy alone can effectively reduce traffic congestion $(\sim 72.22 \%)$ and air pollution $(\sim 68.91 \%)$, thus achieving the dual goals of congestion and emission reduction, but the effect on the number of illegal trips is limited. Thus, the combined penalty and APCF strategy can not only achieve a "win-win" situation of emission reduction ( $68.91 \%)$ and congestion alleviation $(\sim 82.40 \%)$ but also effectively improve the health impact index $(\sim 279.03 \%)$ and reduce the number of illegal trips $(\sim 69.35 \%)$.

Therefore, the combined strategy and integrated algorithm provide theoretical basis and technical support for the governance of urban haze pollution and traffic congestion. Furthermore, can serve as decision-making reference for relevant government departments.

\section{Policy recommendations}

Based on the main conclusions, the following policy recommendations are proposed.

First, continue to strengthen the coordination between the penalty and APCF policy and other policies. On the one hand, we should improve relevant laws and regulations to ensure the implementation effect of the penalty policy and APCF policy. On the other hand, we should vigorously develop urban public transport and improve the subsidy policy, using part of the APCF revenues to subsidize public transport, improve service quality, and improve the supply of public transport to make up for deficiencies in the APCF policy. In addition, we should expand the scope of subsidies, providing subsidies to purchase haze prevention and control products.

Second, increase the source control of vehicle exhaust pollution. Through policies and subsidies, we should encourage the purchase of small displacement cars through preferential policies and subsidies and increase the elimination of old cars. Subsidies and tax incentives can be given to manufacturers and owners of small displacement vehicles to improve public awareness of haze-control strategies. At the same time, at the technical level, the quality of oil products can be improved to achieve emission-reduction goals.

Table 5 Accuracy test

\begin{tabular}{lllrl}
\hline No. & Actual data & Analog data & \multicolumn{1}{l}{ Residual } & Relative error $(\%)$ \\
\hline 2 & $796,379.2823$ & $796,176.5367$ & 202.7456 & 0.0255 \\
3 & $802,349.1675$ & $802,225.7451$ & 123.4224 & 0.0154 \\
4 & $808,124.8443$ & $808,320.9144$ & 196.0701 & 0.0243 \\
5 & $814,028.4354$ & $814,462.3936$ & -433.9582 & 0.0533 \\
6 & $820,637.5722$ & $820,650.5348$ & -12.9626 & 0.0016 \\
7 & $827,270.8750$ & $826,885.6923$ & 385.1827 & 0.0466 \\
8 & $833,128.0000$ & $833,168.2234$ & -40.2234 & 0.0048 \\
\hline
\end{tabular}


Third, update air pollution monitoring data to improve citizens' awareness of environmental protection. Measures for improving air quality can be popularized in the form of brochures, news, radio, and so on. Monitoring data for pollutants can be updated and published on official websites to help the public understand the air quality so they can make reasonable travel decisions. This can also play a supervisory role in air pollutant emissions.

Finally, increase investment in scientific research funds and special funds, foster researchers' enthusiasm for
Emission Control Annual Report (2011-2015), the annual emissions of pollutants $(C O, H C, N O x$, and $P M)$ from vehicles (2011-2018) can be obtained, which are marked as sequence $X_{i}$; then,

$X_{i}=\left(x_{i}(1), x_{i}(2), \cdots, x_{i}(8)\right), i=\mathrm{CO}, \mathrm{HC}, \mathrm{NOx}, \mathrm{PM}$.

Step 2: Organize the data and calculate the corresponding evaluation matrix.

Based on sequence $X_{i}$, the evaluation matrix can be obtained; then,

$A=\left[\begin{array}{c}X_{\mathrm{CO}} \\ X_{\mathrm{HC}} \\ X_{\mathrm{NOx}} \\ X_{\mathrm{PM}}\end{array}\right]=\left[\begin{array}{cccccccc}647664.7 & 683095.1 & 718272.3 & 745748.3 & 754691.2 & 779285.4 & 809699.5 & 833128.0 \\ 72301.1 & 76407.2 & 80456.8 & 83861.2 & 85066.3 & 88045.2 & 91836.9 & 94824.0 \\ 83563.4 & 89465.5 & 95085.9 & 101604.7 & 104582.3 & 109813.8 & 117234.8 & 123536.0 \\ 6957.9 & 7496.6 & 8003.0 & 8651.4 & 8964.1 & 9472.8 & 10214.9 & 10856.0\end{array}\right]$

innovative research, and provide a theoretical basis and technical support for reducing urban traffic congestion and the governance of haze pollution caused by it. Each year, special
Step 3: Calculate the standardized matrix.

Use the interval operator to standardize matrix $A$ and obtain the standardized matrix; then,

$A^{\prime}=\left[\begin{array}{llllllll}0 & 0.19104 & 0.38071 & 0.52886 & 0.57708 & 0.70969 & 0.87368 & 1 \\ 0 & 0.18231 & 0.36211 & 0.51326 & 0.56677 & 0.69903 & 0.86737 & 1 \\ 0 & 0.14765 & 0.28826 & 0.45134 & 0.52583 & 0.65671 & 0.84236 & 1 \\ 0 & 0.13820 & 0.26810 & 0.43444 & 0.51466 & 0.64516 & 0.83554 & 1\end{array}\right]$.

funds should be allocated to support relevant research and development and the optimization of control measures, thereby boosting research progress and playing a leading role in the advancement of science and technology.

Acknowledgements This research was supported by the National Natural Science Foundation of China (grant no. 11901167), Social Science Planning Foundation in Henan Province (grant no. 2019BJJ038), Soft Science Key Research Project of Henan Province (grant no. 202400410051), Soft Science Research Project of Zhengzhou, and Special fund for topnotch talents in Henan Agricultural University (Grant no. 30500646). We thank LetPub (www.letpub.com) for its linguistic assistance during the preparation of this manuscript.

\section{Appendix}

\section{Algorithm steps of the weighted logic function based on the SD-EW-GM approach}

Stage 1: Calculate entropy weight.

Step 1: Data processing.

Based on the China Mobile Source Environmental Management Annual Report (2019), China Vehicle Environmental Management Annual Report (2016-2018), China Vehicle
Step 4: Calculate generalized entropy.

Use Eqs. (1) and (2) to calculate generalized entropy; then,

$\left(H_{\mathrm{CO}}, H_{\mathrm{HC}}, H_{\mathrm{NO}}, H_{\mathrm{PM}}\right)=(0.88897,0.88610,0.87232,0.86775)$.

Step 5: Calculate generalized entropy weight.

$b_{i}=1-H_{i}, e_{i}=b_{i}+\frac{1}{10} \sum_{i=1}^{m} b_{i} ;$ calculate the value of $b_{i}$ and $e_{i}$, and obtain the generalized entropy weight of the $i$ index.

Let $b_{i}=1-H_{i}, \quad e_{i}=b_{i}+\frac{1}{10}\left(b_{\mathrm{CO}}+b_{\mathrm{HC}}+b_{\mathrm{NOx}}+b_{\mathrm{PM}}\right)$; then,

$\left[\begin{array}{c}b_{\mathrm{CO}} \\ b_{\mathrm{HC}} \\ b_{\mathrm{NOx}} \\ b_{\mathrm{PM}}\end{array}\right]=\left[\begin{array}{l}0.11103 \\ 0.11390 \\ 0.12768 \\ 0.13225\end{array}\right], \quad\left[\begin{array}{c}e_{\mathrm{CO}} \\ e_{\mathrm{HC}} \\ e_{\mathrm{NOx}} \\ e_{\mathrm{PM}}\end{array}\right]=\left[\begin{array}{l}0.159516 \\ 0.162386 \\ 0.176166 \\ 0.180736\end{array}\right]$.

Hence,

$\left(\omega_{\mathrm{CO}}, \omega_{\mathrm{HC}}, \omega_{\mathrm{NOx}}, \omega_{\mathrm{PM}}\right)=(0.23500,0.23922,0.25952,0.26626)$.

Stage 2: Forecast future data, and take $\mathrm{CO}$ as an example.

Step 6: Use the average weakening buffer operator (Eqs. (7) and (8)) to process the original data.

Assume that 


$$
\begin{aligned}
X_{\mathrm{CO}}= & \left(x_{\mathrm{CO}}(1), x_{\mathrm{CO}}(2), \ldots, x_{\mathrm{CO}}(8)\right) \\
= & (647664.7,683095.1,718272.3,745748.3, \\
& 754691.2,779285.4,809699.5,833128.0) .
\end{aligned}
$$

Then,

$$
\begin{aligned}
X_{\mathrm{CO}}^{(0)}= & \left(x_{\mathrm{CO}}^{(0)}(1), x_{\mathrm{CO}}^{(0)}(2), \ldots, x_{\mathrm{CO}}^{(0)}(8)\right)=(790137.8799,796379.2823, \\
& 802349.1675,808124.8443,814028.4354,820637.5722, \\
& 827270.8750,833128.0000) .
\end{aligned}
$$

Step 7: Calculate the sequence of analog values.

Use Model GM $(1,1)$ to calculate the sequence of analog values and obtain

$$
\left\{\begin{array}{l}
\hat{x}_{\mathrm{CO}}^{(1)}(k+1)=104367311.8799 e^{0.0076 k}-103577174.9342 \\
\hat{Y}(k+1)=\hat{x}_{\mathrm{CO}}^{(0)}(k+1)=\hat{x}_{\mathrm{CO}}^{(1)}(k+1)-\hat{x}_{\mathrm{CO}}^{(1)}(k), \quad k=1,2,3, \ldots, 8 .
\end{array}\right.
$$

Step 8: Accuracy test.

Table 5 shows the average relative error between the analog value sequence and the real value sequence. According to the calculation results, the average relative error is $0.0245 \%$.

Step 9: Forecast future data.

According to the results from step 8 , the average relative error is within the controllable range, and the data in the next seven years can be calculated. Then,
Based on the actual air pollution in Beijing after 2011, the values are assigned.

Step 12: Establish the logic function.

According to step 11, use VENSIM software (Zhong et al. 2013) to establish the logic function and obtain the pollution degree of $\mathrm{CO}$; then,

Pollution degree of $\mathrm{CO}=$ IF THEN ELSE(Number of CO generation $>=878502.9848,0.95$, IF THEN ELSE(Number of CO generation $>=871878.6055$, 0.94, IF THEN ELSE(Number of CO generation $>=865304.1775,0.93$, IF THEN ELSE(Number of CO generation $>=858779.3242,0.92$, IF THEN ELSE(Number of CO generation $>=852303.6717$, 0.91, IF THEN ELSE(Number of CO generation $>=845876.8491,0.9$, IF THEN ELSE(Number of CO generation $>=839498.4881,0.88$, IF THEN ELSE(Number of CO generation $>=833128$, 0.85 , IF THEN ELSE(Number of CO generation $>=809699.5,0.8$, IF THEN ELSE(Number of CO generation $>=779285.4,0.75$, IF THEN ELSE(Number of CO generation $>=754691.2,0.7$, IF THEN ELSE(Number of CO generation $>=745748.3$, 0.65, IF THEN ELSE(Number of CO generation $>=718272.3,0.6$, IF THEN ELSE(Number of CO generation $>=683095.1,0.55$, IF THEN

$$
\begin{aligned}
\hat{Y}_{C O} & =\left(y_{\mathrm{CO}}(2019), y_{\mathrm{CO}}(2020), y_{\mathrm{CO}}(2021), y_{\mathrm{CO}}(2022), y_{\mathrm{CO}}(2023), y_{\mathrm{CO}}(2024), y_{\mathrm{CO}}(2025)\right) \\
& =(839498.4881,845876.8491,852303.6717,858779.3242,865304.1775,871878.6055,878502.9848) .
\end{aligned}
$$

\section{Stage 3: Establish the weighted logic function.}

Step 10: Establish a new sequence based on the original value and its predicted value.

The original value and the predicted value are combined into a new sequence; then,

$$
Y_{\mathrm{CO}}=\left[\begin{array}{c}
x_{\mathrm{CO}}(1) \\
x_{\mathrm{CO}}(2) \\
\vdots \\
x_{\mathrm{CO}}(8) \\
y_{\mathrm{CO}}(2019) \\
y_{\mathrm{CO}}(2020) \\
\vdots \\
y_{\mathrm{CO}}(2025)
\end{array}\right]=\left[\begin{array}{c}
647664.7000 \\
683095.1000 \\
718272.3000 \\
745748.3000 \\
754691.2000 \\
779285.4000 \\
809699.5000 \\
833128.0000 \\
839498.4881 \\
845876.8491 \\
852303.6717 \\
858779.3242 \\
865304.1775 \\
871878.6055 \\
878502.9848
\end{array}\right] .
$$

Step 11: Divide the pollution grade.
ELSE(Number of CO generation $>=647664.7,0.5$, IF THEN ELSE(Number of CO generation $>=615413.6$, 0.45, IF THEN ELSE(Number of CO generation $>=510540.7,0.35$, IF THEN ELSE(Number of CO generation $>=44(882.1,0.3,0.2(2))))))))))))$ )) ))).

Repeat steps 6-11. This can calculate the pollution degree of HC, pollution degree of NOx, and pollution degree of PM.

Step 13: Build the weighted logic function.

According to the calculation results of step 5 and step 12, we can obtain the degree of air pollution:

\footnotetext{
Degree of air pollution $=0.23500 \cdot$ pollution degree of $\mathrm{CO}$ $+0.23922 \cdot$ pollution degree of $\mathrm{HC}+0.25952 \cdot$ pollution degree of $\mathrm{NOx}+0.26626 \cdot$ pollution degree of PM.
}

\section{References}

Beijing Statistical Yearbook (2009-2019). http://tjj.beijing.gov.cn/ Borjesson M, Kristoffersson I (2015) The Gothenburg congestion charge. Effects, design and politics. Transp Res A 75:134-146. https://doi.org/10.1016/j.tra.2015.03.011 
Borjesson M, Eliasson J, Hamilton C (2016) Why experience changes attitudes to congestion pricing: the case of Gothenburg. Transp Res A 85:1-16. https://doi.org/10.1016/j.tra.2015.12.002

Chen SY, Chen DK (2018) Air pollution, government regulations and high-quality economic development. Econ Res J 53(2):20-34 (in Chinese)

Cheung CW, He GJ, Pan YH (2020) Mitigating the air pollution effect? The remarkable decline in the pollution-mortality relationship in Hong Kong. J Environ Econ Manag 101:102316. https://doi. org/10.1016/j.jeem.2020.102316

China Statistical Yearbook (2009-2019). http://www.stats.gov.cn/tjsj/ ndsj/

Eliasson J (2009) A cost-benefit analysis of the Stockholm congestion charging system. Transp Res A 43(4):468-480. https://doi. org/10.1016/j.tra.2008.11.014

Eliasson J, Borjesson M, Amelsfort DV, Brundell-Freij K, Engelson L (2013) Accuracy of congestion pricing forecasts. Transp Res A 52:34-46. https://doi.org/10.1016/j.tra.2013.04.004

Gopinath Menon AP, Kiankeong C (2004) ERP in Singapore-What's been learnt from five years of operation? Traffic Inform Eng Control 45(2):62-66

Hao Y, Peng H, Temulun T et al (2018) How harmful is air pollution to economic development? New evidence from $\mathrm{PM}_{25}$ concentrations of Chinese cities. J Clean Prod 172:743-757. https://doi. org/10.1016/j.jclepro.2017.10.195

Jia SW, Liu XL, Yan GL (2019) Effect of APCF policy on the haze pollution in China: a system dynamics approach. Energy Policy 125:33-44. https://doi.org/10.1016/j.enpol.2018.10.012

Li Y, Guan DB, Tao S, Wang X, He K (2018) A review of air pollution impact on subjective well-being: survey versus visual psychophysics. J Clean Prod 184:959-968. https://doi.org/10.1016/j.jclep ro.2018.02.296

Liu SF (2017) Grey system theory and application. Science Press, Beijing, China (in Chinese)

Lotrecchiano N, Sofia D, Giuliano A, Barletta D (2019) Real-time onroad monitoring network of air quality. Chem Eng Trans 74:241246. https://doi.org/10.3303/CET1974041

Ministry of Environmental Protection (MEP) of the People's Republic of China (2011-2015) China vehicle emission control annual report. http://www.mee.gov.cn/hjzl/sthjzk/ydyhjgl/

Ministry of Environmental Protection (MEP) of the People's Republic of China (2016-2018) China vehicle environmental management annual report. http://www.mee.gov.cn/hjzl/sthjzk/ydyhjgl/
Ministry of Environmental Protection (MEP) of the People's Republic of China (2019) China mobile source environmental management annual report. http://www.mee.gov.cn/hjzl/sthjzk/ydyhjgl/

Ottosen T, Kumar P (2020) The influence of the vegetation cycle on the mitigation of air pollution by a deciduous roadside hedge. Sustain Cities Soc 53:101919. https://doi.org/10.1016/j.scs.2019.101919

Santos G, Shaffer B (2004) Preliminary results of the London congestion charging scheme. Public Works Manag Policy 9:164-181. https://doi.org/10.1177/1087724X04268569

Schade J, Baum M (2007) Reactance or acceptance? Reactions towards the introduction of road pricing. Transp Res A 41(1):41-48. https ://doi.org/10.1016/j.tra.2006.05.008

Sofia D, Gioiella F, Lotrecchiano N, Giuliano A (2020) Cost-benefit analysis to support decarbonization scenario for 2030: a case study in Italy. Energy Policy 137:111137. https://doi.org/10.1016/j. enpol.2019.111137

Wu Y, Zhang SJ, Hao JM et al (2017) On-road vehicle emissions and their control in China: a review and outlook. Sci Total Environ 574:332-349. https://doi.org/10.1016/j.scitotenv.2016.09.040

Xiao CC, Chang M, Guo PK, Chen Q, Tian X (2019) Comparison of the cost-effectiveness of eliminating high-polluting old vehicles and imposing driving restrictions to reduce vehicle emissions in Beijing. Transp Res D 67:291-302. https://doi.org/10.1016/j. $\operatorname{trd} .2018 .10 .006$

Zhang JL, Ren J (2011) The deficiencies and amendments of the calculation formulate of entropy and entropy weight in the theory of entropy. Stat Inform Forum 26(1):3-5 (in Chinese)

Zhang SL, Li Y, Hao Y, Zhang YP (2018) Does public opinion affect air quality? Evidence based on the monthly data of 109 prefecture-level cities in China. Energy Policy 116:299-311. https://doi. org/10.1016/j.enpol.2018.02.025

Zhong YG, Jia XJ, Qian Y (2013) System dynamics. Science Press, Beijing, China (in Chinese)

Zhu MH (2013) Research on socio-economic impact of urban traffic congestion. Doctoral dissertation. Beijing Jiaotong University (in Chinese)

Zhu YJ, Xie JG, Huang FM, Cao LQ (2020) Association between short-term exposure to air pollution and COVID-19 infection: evidence from China. Sci Total Environ 727:138704. https://doi. org/10.1016/j.scitotenv.2020.138704

Publisher's Note Springer Nature remains neutral with regard to jurisdictional claims in published maps and institutional affiliations. 